Article

\title{
Cluster Enterprise Comprehensive Risk Assessment: Methodology Based on the Functional-Target Approach
}

\author{
Yulia Vertakova ${ }^{1, * \mathbb{C}}$, Irina Izmalkova ${ }^{2}$ and Evgeniy Leontyev ${ }^{3}$ \\ 1 Scientific and Methodological Center, Voronezh State University of Forestry and Technologies Named after G. \\ F. Morozov, 8 Timiryazeva Street, 394087 Voronezh, Russia \\ 2 Lipetsk Branch, Financial University under the Government of the Russian Federation, \\ 12B Internatsionalnaya Street, 398050 Lipetsk, Russia; izmalkova.02@mail.ru \\ 3 Department of the Technical and Socio-Economic Profile Specialties, Kursk State Agricultural Academy \\ Named after I. I. Ivanov, 70 Karl Marx Street, 305021 Kursk, Russia; leo88kgsha@mail.ru \\ * Correspondence: vertakova7@yandex.ru
}

check for updates

Citation: Vertakova, Yulia, Irina Izmalkova, and Evgeniy Leontyev. 2022. Cluster Enterprise Comprehensive Risk Assessment: Methodology Based on the Functional-Target Approach. Journal of Risk and Financial Management 15: 15. https://doi.org/10.3390/ jrfm15010015

Academic Editor: Thanasis Stengos

Received: 7 November 2021

Accepted: 1 January 2022

Published: 4 January 2022

Publisher's Note: MDPI stays neutral with regard to jurisdictional claims in published maps and institutional affiliations.

Copyright: (C) 2022 by the authors. Licensee MDPI, Basel, Switzerland. This article is an open access article distributed under the terms and conditions of the Creative Commons Attribution (CC BY) license (https:// creativecommons.org/licenses/by/ $4.0 /)$.

\begin{abstract}
The effectiveness of the unification of enterprises in the cluster is also associated with high uncertainty and risks. Thus, the development of theoretical approaches and methodological instruments for efficient risk management of enterprises under the conditions of cluster association is an urgent scientific task. The methodology of a comprehensive risk assessment of the cluster enterprise is based on the use of the approach for building a functional-target model of a cluster enterprise, and is reduced to the search for a response to the question: can an event change the value of a providing indicator in such a way that this will lead to a deterioration in the resulting indicator in each enterprise subsystem? Based on the results of forecasting external risks, it was established that the group of state and global risks, in particular, political, territorial and financial, is characterized by significant threats for the next 5 years for the studied cluster enterprises. We proposed and tested a methodology for a comprehensive assessment of the risks of cluster enterprises, based on a functional-target approach, according to which a cluster enterprise as a socio-economic system is considered as a set of three basic subsystems: management, production and financial and economic.
\end{abstract}

Keywords: methodology; risks; assessment; risk management; cluster; enterprise

\section{Introduction}

World economic science considers cluster associations as an effective tool for increasing the effectiveness and sustainability of individual enterprises. An economic cluster is a dense network of companies and institutions in a certain geographic sphere. The cluster is composed of production companies, raw materials suppliers, services providers, companies in related fields and public institutions (Porter 1998). In this work, a cluster is an amalgamation of enterprises. As for the question of the nature of the association (sectoral or territorial), the proposed methodology is suitable for any type of cluster, of course, adjusted for the specifics of activities and environmental conditions.

The formation of clusters in order to distribute risks between the participants of the cluster association seems to be an effective risk management tool. At the same time, the effectiveness of the unification of enterprises in the cluster is also associated with high uncertainty and risks (Jankowiak 2020).

Risk management of integration associations of enterprises has a huge impact on the Russian economy. In the structure of large financial and industrial corporations across the world, risk management units are indispensable elements that ensure the safety and efficiency of production (Galtsova et al. 2020). Russian companies often try to turn risk management into an auxiliary function, they limit themselves to identifying and ranking risks, not paying sufficient attention to the analysis and processing of the strategy (Zaripov 
and Murakaev 2018). Most Russian companies lack competent specialists in the field of risk management.

An incomplete assessment and, as a result, ineffective risk management leads to the failure of cluster projects and large financial losses for the participants. Thus, the development of theoretical approaches and methodological instruments for efficient risk management of enterprises under the conditions of cluster association is an urgent scientific task.

Managing the economic risks of integration enterprises is by its nature extremely difficult since corporations have both unhedged production risks and hedged market risks (foreign exchange, interest rates, the impact of stock prices) (Havierniková and Klučk 2019). If financial managers tend to manage the value of assets and liabilities, then corporate managers give preference to such factors as the growth and instability of the financial results of the corporation (income, cash flows) (Tinyakova et al. 2020). Compared to financial institutions that generate operating income through risky short-term positions, corporations are less sensitive to daily market fluctuations and focus on monthly and quarterly changes in earnings when assessing firm performance.

An analysis of the risks that threaten the activities of enterprises of various organizational and legal forms allows us to conclude that the specificity of risk management of integrated business associations is not only in the presence of special types of economic risks, the impact of which must be taken into account in activities, but also in the originality of the procedures for managing such risks, associated with the structure of the integration association (Havierniková and Kordoš 2019).

Integration associations of enterprises (in particular clusters) are under the influence of numerous risks since the business is characterized by an orientation for an outdated risk management paradigm: a reactive approach (work with risks that have already become a problem), while leading companies have long since moved to a new level of understanding of the management logic risk: a preventive approach to risk management tasks (working with risks that have not yet become problems) (Cooke 2001).

We analyzed scientific publications that are devoted to risk management and include sections that directly relate to the risk diagnosis process (Sun et al. 2019). It should be noted that most of the methods of identifying the risks presented in modern scientific works (Aven and Nøkland 2010; Zhang 2017) are a substantiation of the method of obtaining the information necessary for the process of their diagnosis. Moreover, these methods are systematized only to collect information relating to risks of the loss of property objects (Martin and Sunley 2003). This comes from the idea that these methods were "brought" in the sphere of risk management of the enterprise for insurance cases, the history of the development of which is not from just one century (Guzhin and Ezhkova 2017).

In most scientific papers illuminating risk topics in the context of risk diagnostics, there are general recommendations for the approach to this procedure ("use the above risk classifications", "to concentrate attention on the events on which the company's profit depends", etc.) or description methods for collecting risk-oriented information about the object under study (questionnaires, interviews, analysis of primary documents, financial and statistical reporting, etc.) (Williams 1989). As a result, when using such theoretical and methodological support, managers have difficulties with the process of diagnosing the risks of the enterprise (Bell 2005).

In our opinion, more attention should be paid to the diagnosis of enterprises' activity, taking into account risks on micro and macro levels, covering not only theoretical and methodological aspects but also practical aspects of the application of the risk diagnosis model in the enterprise. At the same time, the studied enterprises and the participants in the cluster's formation have significant specificity from the point of view of their contribution to the results of the cluster's functioning, and the cluster structure itself has a synergistic effect (positive or negative), which certainly requires accounting for when developing risk assessment techniques (Keshk et al. 2018). 
The most suitable method for undertaking the process of diagnosing the risks of enterprises in a cluster structure is, in our opinion, the classification of areas of activity, which is based on the idea of an invariant structure of a business entity (Aven 2016). Its essence lies in the fact that the functioning of any enterprise is ensured by the aggregate interaction of production and technology, financial and economic, management, ecological and social systems (Shidov et al. 2019).

The target function of the production and technological system of the enterprise is the transformation of raw materials into finished products with specified parameters; the financial and economic system is focused on increasing income over expenses through the manufacture of products and ensuring the uninterrupted flow of cash; the social system is focused on ensuring the development of the professional and personal potential of employees and their effective use in all areas of the enterprise; the ecological system is focused on preserving the quality of the natural environment and eliminating the negative impact on it; the management system is focused on ensuring coordinated effective (not only in economic, but also in social, environmental and other aspects) functioning of the enterprise as a whole, as well as all of its subsystems (Deif and Mohib 2020).

At the same time, the management system coordinates the work of all other systems, as well as the relationships between them (Delgado et al. 2014). This fact reflects the most important, in our opinion, and most specific feature of management: the achievement of the desired results of the activities of enterprises within a cluster association of enterprises is possible only if the interaction of all of its systems is implemented (Vertakova and Klevtsova 2016).

The list of systems proposed above was used by us as a basis for building a functionaltarget model of a cluster enterprise. The graphic representation of the basic systems of the enterprises of the cluster according to the functional-target approach is shown in the Figure 1.

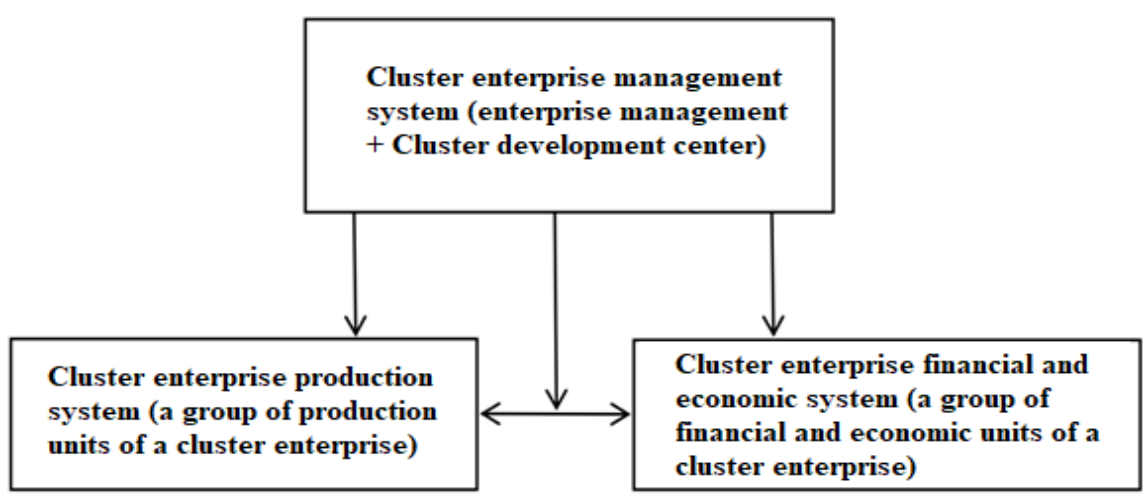

Figure 1. Basic systems of the cluster enterprise according to the functional-target approach. Developed by Izmalkova I.

The combination of the reduced systems is, in our opinion, necessary and sufficient for the functioning of any cluster enterprise, regardless of its scale, scope of activity and other individual characteristics. Thus, these systems are basic (minimally sufficient) for the functioning of the cluster enterprise (Bell 2005).

\section{Materials and Methods}

The methodology of a comprehensive risk assessment of an enterprise in the cluster structure is based on the use of the approach proposed above, and is reduced to the search for a response to the question: can an event change the value of a providing indicator (PI) in such a way that this will lead to a deterioration in the resulting indicator (RI) in each enterprise subsystem. A set of answers to this question, obtained by all providing indicators, will be a basic risk spectrum of a cluster association (Vertakova et al. 2019). 
It is important that many possible options for answers are limited by the "coordinates" of the risk deferred on the "axes" represented by indicators of sources of possible risks (PI enterprises/systems) and risk exposures (risk implementation areas) characterized by the relevant RI of the enterprises/systems. Information on the "coordinates" of risk is quite complete (which is ensured by using a list of risky projections and risk sources that cover all basic areas of generation and realization of risks, as well as the presence of rules for detailing these lists), as well as systematized (in the context of the enterprise, its systems and elements of systems). Thus, the risk-oriented system of indicators proposed by us allows us to regulate and significantly simplify the procedure for diagnosing the risks of the cluster enterprise (Vertakova et al. 2014).

A tool that largely allows you to streamline the procedure for diagnosing risks in practice is the diagnostic matrix presented in Figure 2.

The algorithm for the process of integrative diagnostics and assessment of the risks of the enterprise and its systems based on the proposed SDP is reduced to the following steps.

1. Receiving an answer to the question "What event can change the value of a PI of the enterprise in such a way that it will negatively affect the value of the enterprise RI that corresponds to it?" The risks diagnosed due to the deterioration of the enterprise's PI are identified.

2. A comprehensive analysis of the risks of negative deviation from the RI diagnosed on the deterioration of PI enterprises in order to identify their causal relationships, as well as the exclusion of risk duplication facts. In the process of analysis, the degree of mutual influence of the PI and RI should also be taken into account.

3. The values of the risks diagnosed for the deterioration of PI systems including the enterprises as a whole are calculated. The risk values of the negative deviation from the RI of systems are calculated (the risks identified by the worsening of PI systems for each of the RI). The risks of the enterprise are calculated (the values of the risks of the negative deviation from the RI due to the deterioration of the PI enterprise).

\begin{tabular}{|c|c|c|c|c|c|c|c|c|}
\hline$R_{11}$ & $\mathrm{R}_{12}$ & $\mathrm{R}_{13}$ & $\mathrm{R}_{14}$ & $\mathrm{R}_{15}$ & $\mathrm{R}_{16}$ & \multirow{10}{*}{ 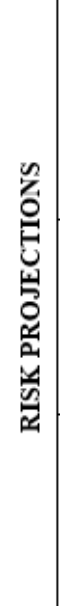 } & \multirow{4}{*}{ 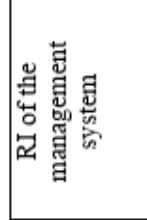 } & The volume of products sold \\
\hline $\mathrm{R}_{21}$ & $\mathrm{R}_{22}$ & $\mathrm{R}_{23}$ & $\mathrm{R}_{24}$ & $\mathrm{R}_{25}$ & $\mathrm{R}_{26}$ & & & Expenses of the management system \\
\hline $\mathrm{R}_{31}$ & $\mathrm{R}_{32}$ & $\mathrm{R}_{33}$ & $\mathrm{R}_{34}$ & $\mathrm{R}_{35}$ & $\mathrm{R}_{36}$ & & & Performance level of production system \\
\hline $\mathrm{R}_{41}$ & $\mathrm{R}_{42}$ & $\mathrm{R}_{43}$ & $\mathrm{R}_{44}$ & $R_{45}$ & $\mathrm{R}_{46}$ & & & $\begin{array}{l}\text { Performance level of financial } \\
\text { and economic system }\end{array}$ \\
\hline $\mathrm{R}_{51}$ & $\mathrm{R}_{52}$ & $\mathrm{R}_{53}$ & $\mathrm{R}_{54}$ & $\mathrm{R}_{55}$ & $\mathrm{R}_{56}$ & & \multirow{3}{*}{ 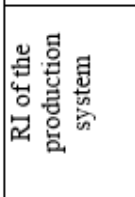 } & $\begin{array}{l}\text { Performance of the production } \\
\text { plan }\end{array}$ \\
\hline $\mathrm{R}_{61}$ & $\mathrm{R}_{62}$ & $\mathrm{R}_{63}$ & $\mathrm{R}_{64}$ & $\mathrm{R}_{65}$ & $\mathrm{R}_{66}$ & & & $\begin{array}{l}\text { Quality of the resource infrastructure of } \\
\text { the cluster }\end{array}$ \\
\hline $\mathrm{R}_{71}$ & $\mathrm{R}_{72}$ & $\mathrm{R}_{73}$ & $\mathrm{R}_{74}$ & $\mathrm{R}_{75}$ & $\mathrm{R}_{76}$ & & & Expenses of the production system \\
\hline$R_{81}$ & $\mathrm{R}_{82}$ & $\mathrm{R}_{83}$ & $\mathrm{R}_{84}$ & $R_{85}$ & $\mathrm{R}_{86}$ & & \multirow{3}{*}{ 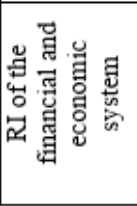 } & $\begin{array}{l}\text { Financial flow management } \\
\text { efficiency }\end{array}$ \\
\hline $\mathrm{R}_{91}$ & $\mathrm{R}_{92}$ & $\mathrm{R}_{93}$ & $\mathrm{R}_{94}$ & $\mathrm{R}_{95}$ & $\mathrm{R}_{96}$ & & & Expenses of the production system \\
\hline $\mathrm{R}_{101}$ & $\mathrm{R}_{102}$ & $\mathrm{R}_{103}$ & $\mathrm{R}_{104}$ & $\mathrm{R}_{105}$ & $\mathrm{R}_{106}$ & & & $\begin{array}{l}\text { Expenses of the financial and economic } \\
\text { system }\end{array}$ \\
\hline \multicolumn{6}{|c|}{ RISK SOURCES INDICATORS } & & & \\
\hline \multicolumn{3}{|c|}{ External environment } & \multicolumn{3}{|c|}{ Internal environment } & & & \\
\hline 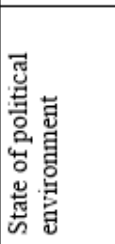 & 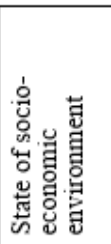 & 层 & 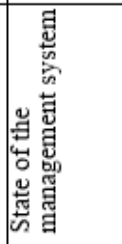 & 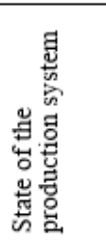 & 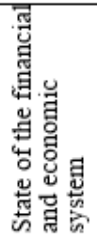 & & & \\
\hline
\end{tabular}

Figure 2. Basic systems of the cluster enterprise according to the functional-target approach. Developed by Izmalkova I. 
Approbation of the mechanism of application of the proposed methodology for assessing the risks of the cluster enterprise was carried out with the enterprises-participants in the innovative territorial cluster of mechanical engineering and metalworking of the Lipetsk region known as the "Valley of Mechanical Engineering".

The results of diagnostics with respect to these enterprises were rather homogeneous, so separately they were not distinguished, but were combined by us in order to show the possibilities of using the obtained technique for a typical cluster member company (Folch-Calvo et al. 2020).

Quantitative and qualitative assessment and subsequent analysis of the risks of cluster enterprises require, as well as the use of statistical methods, the settlement, analysis and attraction of methods based on experience and intuition, that is, heuristic or expert assessments (Feser 1998). They feature a lack of strict mathematical evidence, and the general direction of expert methods is to use a person as a peculiar "measuring" device to obtain quantitative estimates of processes and judgments, due to the incompleteness and unreliability of available information that cannot be directly measured (Turkina and Van Assche 2018).

The general algorithm of the expert survey, offered by us to study the risks of industrial enterprises of the cluster, includes the following main stages:

(1) the selection of experts and the formation of expert groups: Group 1, employees of research institutions and higher education institutions of the cluster; Group 2, employees of enterprises (senior and middle level); Group 3, employees of enterprises (low management, professionals, specialists, workers);

(2) formation of issues and compiling a questionnaire;

(3) work with experts (clarification of the essence of individual issues of the questionnaire, rules and procedures for filling in the questionnaire);

(4) the formation of rules for determining the total estimates on the basis of assessments of individual experts;

(5) analysis and processing of results of expert assessments.

Among the key goals of expert assessment should be allocated:

- $\quad$ establishment (identification) of possible significant risks;

- evaluation of sources and risk factors;

- $\quad$ assessment of the probability of risky events;

- $\quad$ establishing relative importance (significance) risky events and risk ranking;

- aggregation of various risks in logical-structural groups;

- $\quad$ evaluation of events and phenomena and predicting the course of their development in the future;

- identification of risk reduction paths;

- analysis and synthesis of results obtained from various expert groups;

- drawing up the development scenarios of the system under study;

- development of effective management solutions.

To assess the degree of risk of individual groups, we propose to use the method of analogies, expert and analytical methods.

We propose to assess the risks of a cluster enterprise according to three criteria:

(1) the probability of the risk situation $\left(P_{R}\right)$;

(2) the degree of possible negative impact on the achievement of the goal $\left(\mathrm{NI}_{G}\right)$;

(3) the weight of the goal in the general system of goals of the enterprise $\left(W_{G}\right)$.

Accordingly, the value of risk $(R)$ should be determined by a systematic analysis of a set of three elements

$$
R=\left\{P_{R} ; N I_{G} ; W_{G}\right\}
$$


Graphical interpretation of the three-criteria spatial model for assessing the risk of a cluster enterprise is shown in Figure 3.

Differentiation of the assessment space in the coordinates $P_{R}, N I_{G}, W_{G}$ by the corresponding subspaces, made it possible to identify points and octants that reflect the situation of risk (at different levels of risk), imminent threat, as well as a risk-free area.

We propose to carry out risk assessment using the following formula

$$
R=P_{R} \times\left(\propto_{1} \times N I_{G}+\propto_{2} \times W_{G}\right)
$$

where $\alpha_{1}, \propto_{2}$ are the weight coefficients of the second and third evaluation criteria.

In this case, the probability of the occurrence of a risk event PR is traditionally determined in the interval $(0 ; 1)$. To determine the criteria for NIG and WG (price of risk), we will use a 100-point rating scale. The sum of the weighting factors must be equal to 1 .

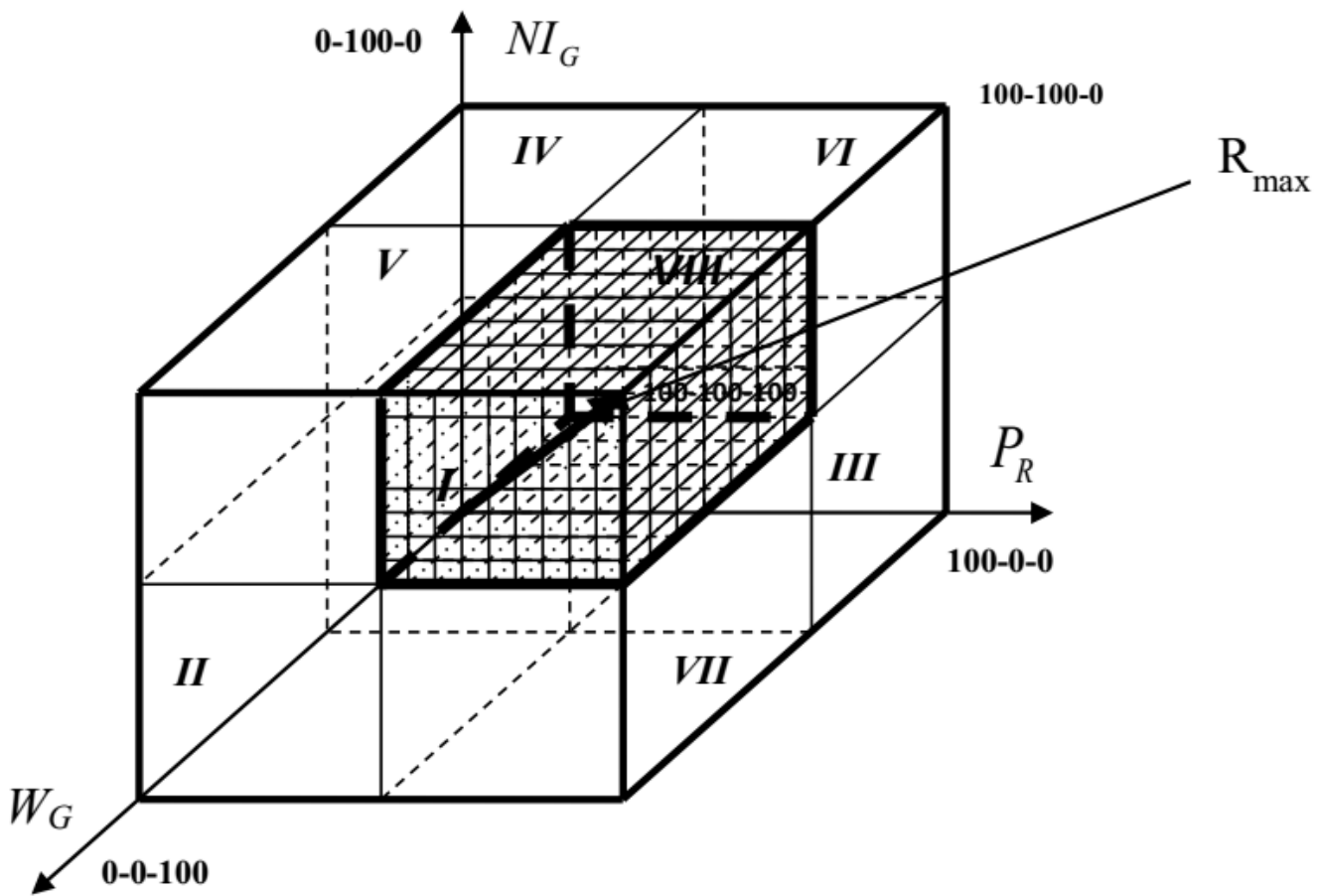

Figure 3. Graphical interpretation of a three-criteria spatial model for assessing the risk of an enterprise in a cluster developed by Izmalkova I. and Vertakova Yu.

The advantages of such a three-criterion risk assessment are its versatility (the possibility of using it to assess risks of any level: from operational to strategic); the ability to analyze situations of both full and partial risk realization; consideration of a specific type of risk in conjunction with the general system of risks of the enterprise in the cluster.

Thus, the degree of risk can be assessed in a variety of ways, from sophisticated probabilistic analysis to intuitive assumptions. In modern conditions, the analysis of economic risks should take a key place in the general system of analysis of the production and economic activities of the enterprise. When assessing the risks of an enterprise in a cluster, the value $\left(\alpha_{1} \times \mathrm{NI}_{\mathrm{G}}+\alpha_{2} \times \mathrm{W}_{\mathrm{G}}\right)$ will be considered the "cost of risk" and will be determined in points by means of an expert survey.

Accordingly, the probability of realization of the $j$-th risk and the $i$-th group is proposed to be determined by integrating expert assessments, taking into account the individual level of competence of experts according to the formula 


$$
P_{R}^{i j}=\frac{\sum_{k=1}^{r}\left(p_{i j k} \times K_{i k}\right)}{\sum_{k=1}^{r} K_{i k}}, i=\overline{1, n}, i=\overline{1, m_{i}}
$$

where $p_{i j k}$ is the probability of realization of the $j$-th risk of the $i$-th group as assessed by the $k$-th expert; $K_{i k}$ is the individual level of competence of the $k$-th expert regarding the assessment of risk indicators of the $i$-th group; $i, n$ are the current index and number of risk groups, respectively; $j, m_{i}$ are the current index and the total number of identified risks in the $i$-th group, respectively.

The aggregated risk assessment of the $i$-th group is formed by adding integrated expert estimates of the probabilities of individual operational risks, taking into account the risk price according to the formula

$$
A R_{i}=\frac{\sum_{j=1}^{m_{i}}\left[P_{R}^{i j} \times\left(\alpha_{1} \times N I_{G}^{i j}+\alpha_{2} \times W_{G}^{i j}\right)\right]}{\sum_{j=1}^{m_{i}}\left(\alpha_{1} \times N I_{G}^{i j}+\alpha_{2} \times W_{G}^{i j}\right)} \times 100, i=\overline{1, n} .
$$

The integrated risk assessment of an enterprise in a cluster can be defined as follows

$$
I R=\frac{\sum_{i=1}^{n}\left(A R_{i} \times Z_{i}\right)}{\sum_{i=1}^{n} Z_{i}}
$$

where $Z_{i}$ is the expert's point estimate of the weight (significance) of the $i$-th risk group.

To establish the acceptable level of risk, the concept of zones (areas) of risk was used. In contrast to four areas of economic risk traditional for industrial enterprises (normal, high, maximum and critical), we proposed a classification using 7 gradations of risk depending on the level of their score and 5 areas of risk (Table 1).

Table 1. Risk grading scale.

\begin{tabular}{ccc}
\hline Score Interval & Risk Grading & Risk Area \\
\hline $0-5$ & background & Risk-free \\
$6-10$ & minimum & \\
$11-30$ & short & Normal risk area \\
$31-40$ & average & high \\
$41-60$ & very tall & High risk area \\
$61-80$ & critical & Very high risk area \\
$81-100$ & & Critical risk area \\
\hline
\end{tabular}

Developed by Leontyev E.

Table 2 provides information on the quantitative and qualitative composition of the respondents who participated in the survey.

As a result of the survey, expert assessments of the probability of the occurrence of risk situations were established, the significance of certain types of risks was assessed, a point assessment of the risks of individual groups was carried out, and the dynamics of changes in the probability of the occurrence of risk situations was determined.

The risk assessment of enterprises in the "Valley of Mechanical Engineering" cluster was carried out according to the performance indicators of JSC STP-Lipetsk Machine-Tool Enterprise, CJSC Lipetsk Machine-Tool Plant "Vozrozhdenie", LLC Litmashpribor. The analysis of the consistency of the opinions of the respondents, carried out using the Kendall concordance coefficient, showed a high degree of consistency of the opinions of experts for all risk groups (average-only in the assessment of cluster risks in the long term). 
Table 2. Quantitative and qualitative composition of respondents.

\begin{tabular}{|c|c|c|}
\hline Group of Respondents & Number, Persons & Specific Gravity, \% \\
\hline Total people, incl. & \multirow[t]{4}{*}{146} & \multirow[t]{4}{*}{100} \\
\hline 1. Personnel of the "Valley of Mechanical & & \\
\hline Engineering" cluster, of which: & & \\
\hline - managers of the highest and middle & & \\
\hline level of the "Valley of Mechanical & \multirow[t]{2}{*}{10} & \multirow[t]{2}{*}{6.85} \\
\hline $\begin{array}{l}\text { Engineering" cluster } \\
\text { - personnel of cluster enterprises }\end{array}$ & & \\
\hline $\begin{array}{l}\text { (managers, professionals, specialists, } \\
\text { workers) }\end{array}$ & \multirow[t]{3}{*}{68} & \multirow[t]{3}{*}{46.58} \\
\hline 2. Scientists and researchers of the & & \\
\hline corresponding profile, of which: & & \\
\hline - doctors of sciences, professors & 10 & 6.85 \\
\hline $\begin{array}{l}\text { - candidates of sciences, associate } \\
\text { professors }\end{array}$ & 24 & 16.44 \\
\hline - candidates of sciences, assistants & 16 & 10.96 \\
\hline - assistants & 18 & 12.33 \\
\hline
\end{tabular}
Developed by Izmalkova I.

\section{Results and Discussion}

The results of the survey of respondents also showed a high level of homogeneity of answers regarding the risks of the activities of the selected enterprises, in connection with which we will not single out the results for each of the enterprises in the work, and also present the average data for a typical industrial enterprise of the "Valley of Mechanical Engineering" cluster (Tables 3-5).

Table 3. The results of an expert assessment of the internal risks of enterprises of the "Valley of Mechanical Engineering" cluster, 2018 year.

\begin{tabular}{|c|c|c|c|c|c|c|}
\hline Risk Type & $P_{R}(0-1)$ & $\begin{array}{c}\mathrm{NI}_{\mathrm{G}} \\
(\mathbf{0}-\mathbf{1 0 0})\end{array}$ & $\propto_{1}$ & $\begin{array}{c}W_{G} \\
(0-100)\end{array}$ & $\propto_{2}$ & $\mathbf{R}$ \\
\hline Financial & 0.48 & 48 & 0.5 & 66 & 0.5 & 27.36 \\
\hline Technical and technological & 0.68 & 46 & 0.4 & 75 & 0.6 & 43.12 \\
\hline Personnel & 0.46 & 32 & 0.5 & 88 & 0.5 & 27.6 \\
\hline Management inefficiencies & 0.42 & 45 & 0.4 & 75 & 0.6 & 26.46 \\
\hline Innovative & 0.35 & 42 & 0.5 & 28 & 0.5 & 12.25 \\
\hline Property & 0.58 & 68 & 0.5 & 78 & 0.5 & 42.4 \\
\hline Informational & 0.32 & 21 & 0.4 & 65 & 0.6 & 15.17 \\
\hline Other & 0.18 & 15 & 0.5 & 20 & 0.5 & 3.15 \\
\hline
\end{tabular}

Developed by Izmalkova I.

Table 4. The results of an expert assessment of the internal risks of enterprises of the "Valley of Mechanical Engineering" cluster, 2020 year.

\begin{tabular}{lcccccc}
\hline \multicolumn{1}{c}{ Risk Type } & $\mathbf{P}_{\mathbf{R}} \mathbf{( 0 - 1 )}$ & $\begin{array}{c}\mathbf{N I}_{\mathbf{G}} \\
(\mathbf{0 - 1 0 0 )}\end{array}$ & $\boldsymbol{\alpha}_{\mathbf{1}}$ & $\begin{array}{c}\mathbf{W}_{\mathbf{G}} \\
(\mathbf{0 - 1 0 0 )}\end{array}$ & $\boldsymbol{\alpha}_{\mathbf{2}}$ & $\mathbf{R}$ \\
\hline Financial & 0.45 & 58 & 0.5 & 75 & 0.5 & 30.2 \\
Technical and technological & 0.77 & 46 & 0.4 & 75 & 0.6 & 48.6 \\
Personnel & 0.54 & 32 & 0.5 & 88 & 0.5 & 32.5 \\
Management inefficiencies & 0.64 & 45 & 0.4 & 75 & 0.6 & 40.8 \\
Innovative & 0.36 & 42 & 0.5 & 78 & 0.5 & 21.6 \\
Property & 0.73 & 68 & 0.5 & 76 & 0.5 & 52.6 \\
Informational & 0.59 & 41 & 0.4 & 75 & 0.6 & 36.5 \\
other & 0.28 & 18 & 0.5 & 20 & 0.5 & 5.5 \\
\hline
\end{tabular}

Developed by Izmalkova I. 
Table 5. The results of an expert assessment of the internal risks of enterprises of the "Valley of Mechanical Engineering" cluster, 2022 year (forecast).

\begin{tabular}{lcccccc}
\hline \multicolumn{1}{c}{ Risk Type } & $\mathbf{P}_{\mathbf{R}} \mathbf{( 0 - 1 )}$ & $\begin{array}{c}\mathbf{N I}_{\mathbf{G}} \\
\mathbf{( 0 - 1 0 0 )}\end{array}$ & $\boldsymbol{\alpha}_{\mathbf{1}}$ & $\begin{array}{c}\mathbf{W}_{\mathbf{G}} \\
\mathbf{( 0 - 1 0 0 )}\end{array}$ & $\boldsymbol{\propto}_{\mathbf{2}}$ & $\mathbf{R}$ \\
\hline $\begin{array}{l}\text { Financial } \\
\text { Technical and }\end{array}$ & 0.48 & 48 & 0.5 & 66 & 0.5 & 27.36 \\
technological & 0.68 & 46 & 0.4 & 75 & 0.6 & 43.12 \\
$\begin{array}{l}\text { Personnel } \\
\text { Management }\end{array}$ & 0.46 & 32 & 0.5 & 88 & 0.5 & 27.6 \\
inefficiencies & 0.42 & 45 & 0.4 & 75 & 0.6 & 26.46 \\
Innovative & 0.35 & 42 & 0.5 & 28 & 0.5 & 12.25 \\
Property & 0.58 & 68 & 0.5 & 78 & 0.5 & 42.4 \\
Informational & 0.32 & 21 & 0.4 & 65 & 0.6 & 15.17 \\
other & 0.18 & 15 & 0.5 & 20 & 0.5 & 3.15 \\
\hline Developed
\end{tabular}

Developed by Izmalkova I.

The analysis of trends in the development of internal risks is characterized by a rapid increase in the magnitude of technical and technological, managerial, property and information risks (Figure 4). Where in 2018 the probability of these risks was assessed by experts as medium, by 2020 the risks were assessed as being high.

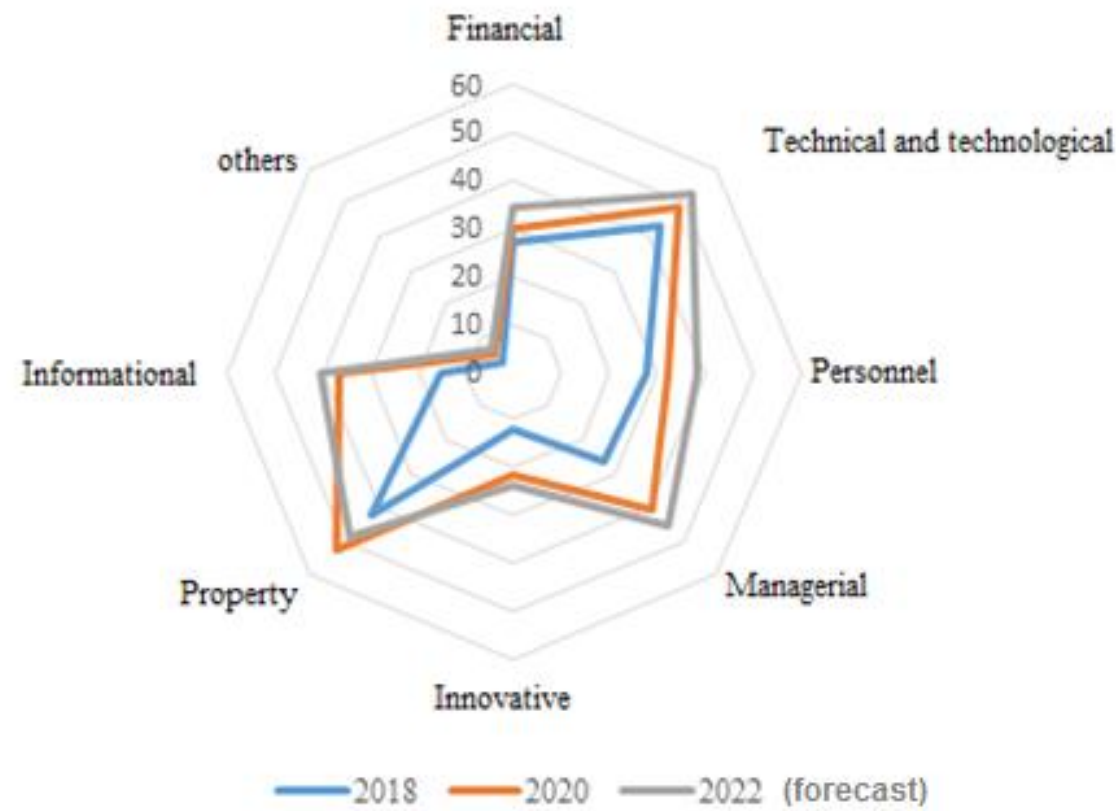

Figure 4. The results of the assessment of the group of internal risks of the enterprises of the cluster. Developed by Izmalkova I. and VertakovaYu.

An alarming signal is that other types of risks are also proposed to grow, but not as intensely. The most dynamic is expected to be the growth of technical, technological and property risks, which are primarily due to the need to update, modernize and reconstruct the fixed assets of enterprises.

Potential threats to the deterioration in the financial and economic activities of cluster enterprises also arise due to ineffective management. It was also found that there is a high probability that these negative trends will persist over the next five years.

Calculations for groups of cluster, intrastate and global risks were carried out in a similar way, the results of which are graphically reflected in Figures 5-7. 


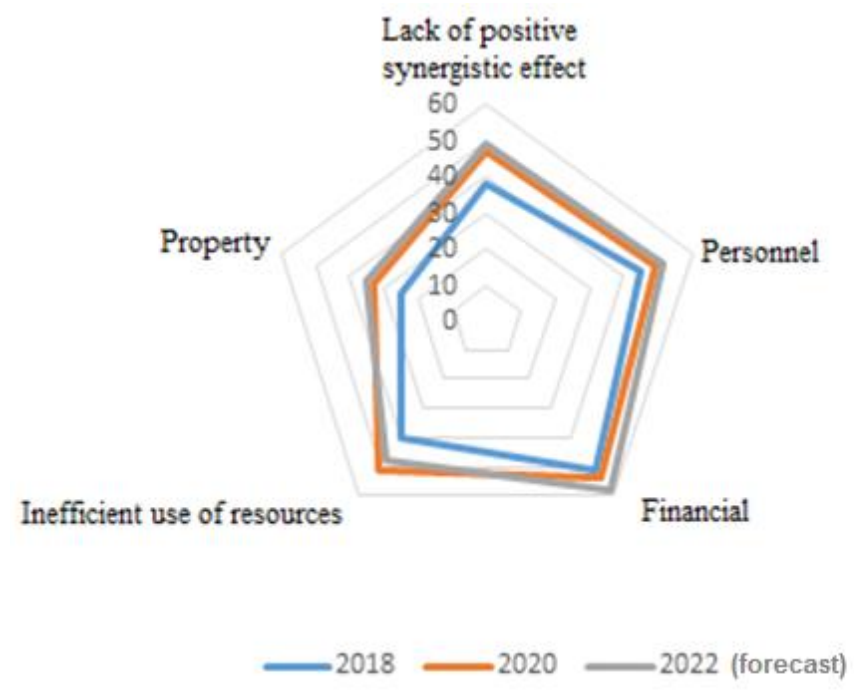

Figure 5. The results of the assessment of the group of cluster risks of the enterprises of the cluster. Developed by Izmalkova I. and Vertakova Yu.

A feature of our research is that in addition to traditional internal and external risks, we have identified a group of cluster risks caused by the operation of the industrial enterprises under study as part of the "Mechanical Engineering Valley" cluster. An expert survey found that significant in this group are financial and personnel risks, the probability of realization of which will steadily grow over the next 5 years.

The experts focused special attention on the threat of the ineffectiveness of personnel appointments to managerial positions and the ineffective allocation of resources. Based on the results of scoring the risks of the cluster's subsystems, one can state that the existing negative trend of growth in threats is caused by the corporate risks in question; in 20182020, these risks belonged to the medium zone, and by 2022 (forecast), these risks had moved to the category of high risk with the preservation of negative trends.

The results of the study of the group intrastate risks are also indicative. They clearly show the growth of political, financial risks, risks of suppliers and consumers in the period from 2018 to 2022 (forecast), which, according to the quantitative estimates of experts, are approaching the border between high and very high risks (Figure 6).

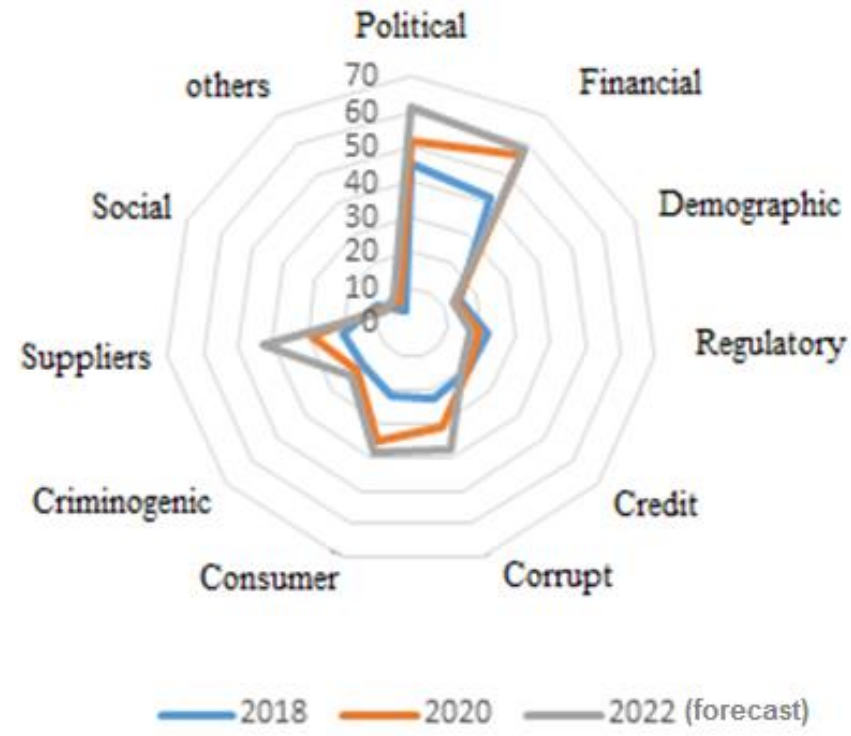

Figure 6. The results of the assessment of the group of intrastate risks of the enterprises of the cluster. Developed by Izmalkova I. and Leontyev E. 
The enterprises of the cluster provide products not only to the domestic but also to the foreign market. Therefore, such factors as political stability, national strategies of individual countries, relationships with suppliers of raw materials, the economic situation in consumer countries and the policy of individual states in the field of diversification of national markets have a significant impact on their production and economic activities.

According to the research results, it has been established that such global risks as regulatory, legislative and demographic risks do not cause disruptions in the operation of the cluster enterprises (Figure 7). However, it has been established that from 2018 to 2022 (forecast) there will be a significant increase in political and territorial risk. This necessitates revising the cluster development strategy for the next 10-20 years.

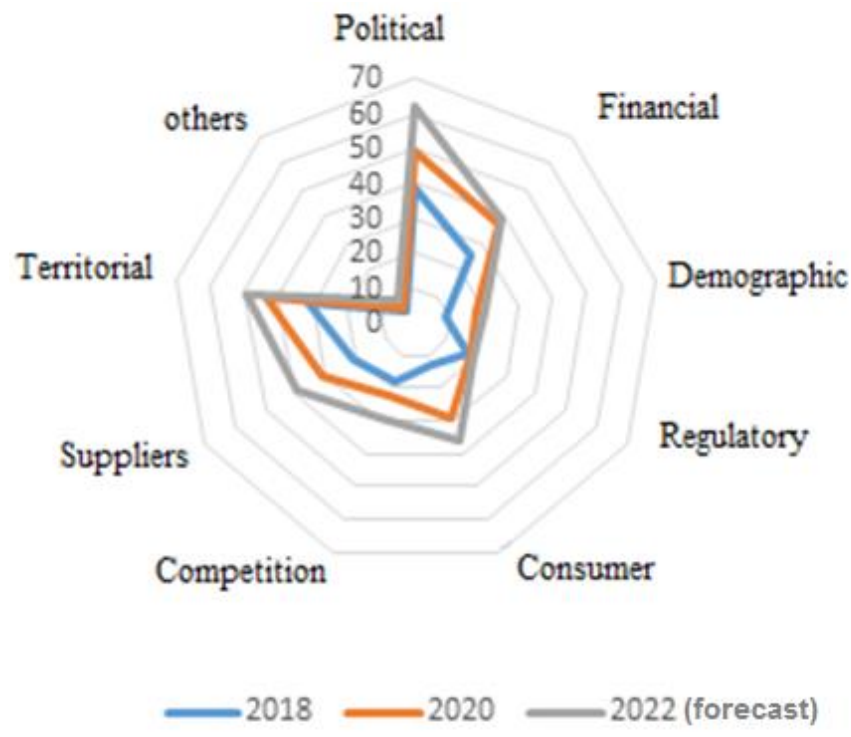

Figure 7. The results of the assessment of the group of global risks of the enterprises of the cluster. Developed by Leontyev E.

As for the "Natural risks" subsystem, the risks identified by us, taking into account the probability of their occurrence and their significance in terms of the scale of potential negative consequences, do not pose a significant threat to the functioning of the enterprises of the "Valley of Mechanical Engineering" cluster, and, within the framework of the adopted gradation, can be attributed to minimum and low risks (Figure 8).
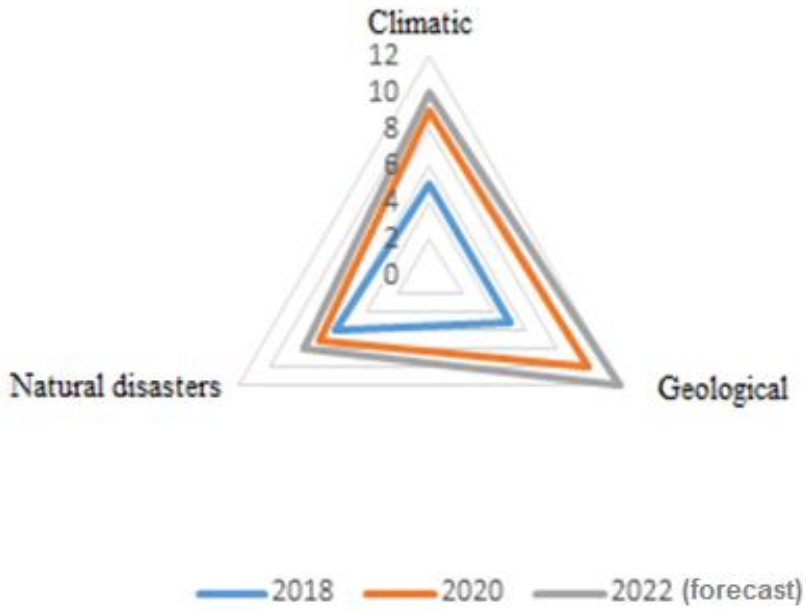

Figure 8. The results of the assessment of the group of natural risks of the enterprises of the cluster. Developed by Leontyev E. 
According to the results of the calculation of aggregated risk subsystems, a negative trend of their growth was established. This, if in 2018 the aggregate risks of most groups were in the zone of medium risks (except for internal and natural, which were characterized by a low level), then in 2022 (forecast) only the group of natural risks belongs to the zone of low risks, while the subgroups of internal, cluster and intrastate risks will shift to the high-risk zone, and global risks, based on the results of expert assessments, will move to the very high-risk zone (Figure 9).

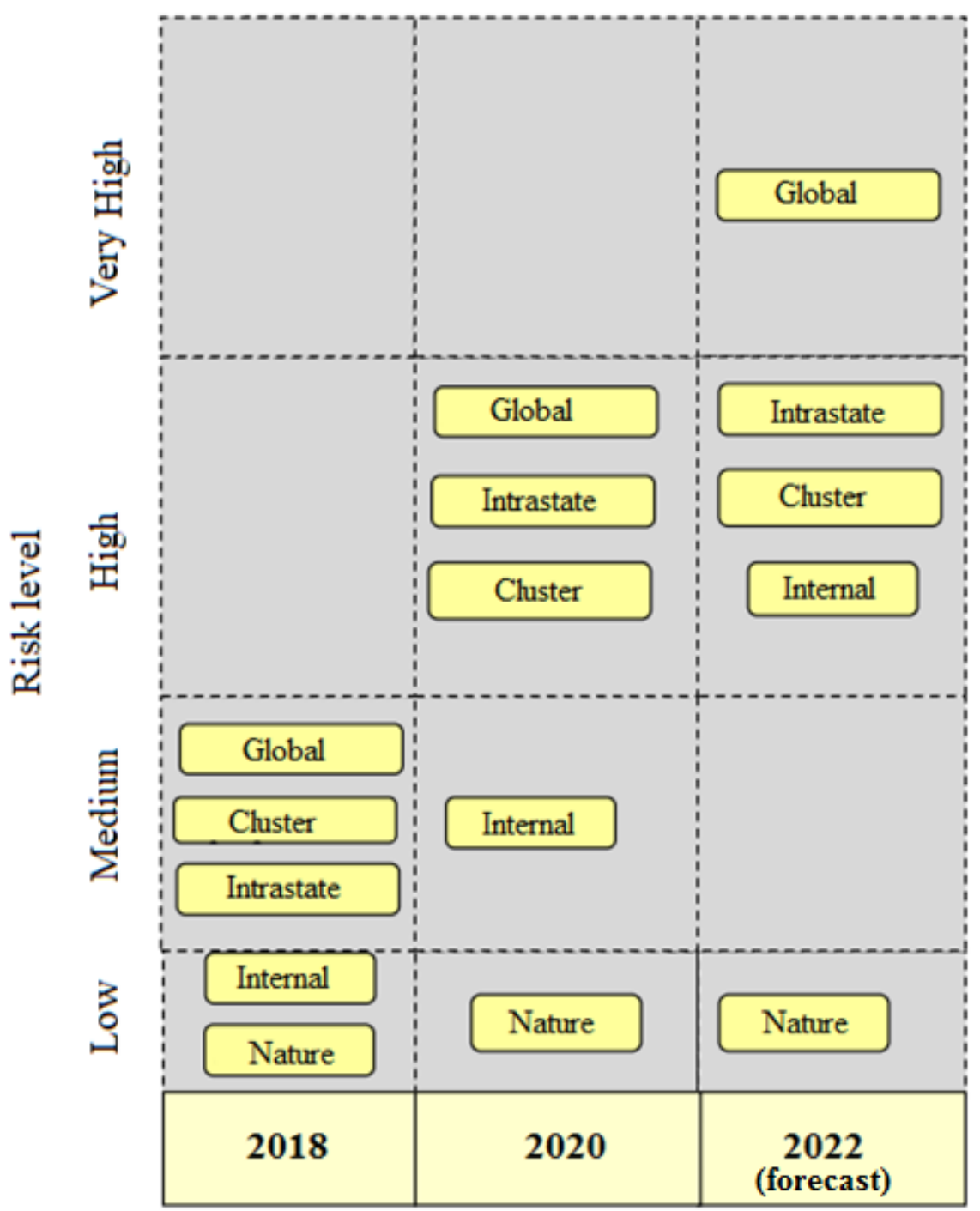

Figure 9. Dynamics of aggregated risk groups of cluster enterprises. Developed by Izmalkova I.

The integral risk assessment of the "Mechanical Engineering Valley" cluster, carried out by aggregating the risks of individual enterprises and taking into account their significance, made it possible to establish a general trend of the influence of both internal and external threats on the production and economic activities of enterprises that are part of the cluster, Figure 10. 


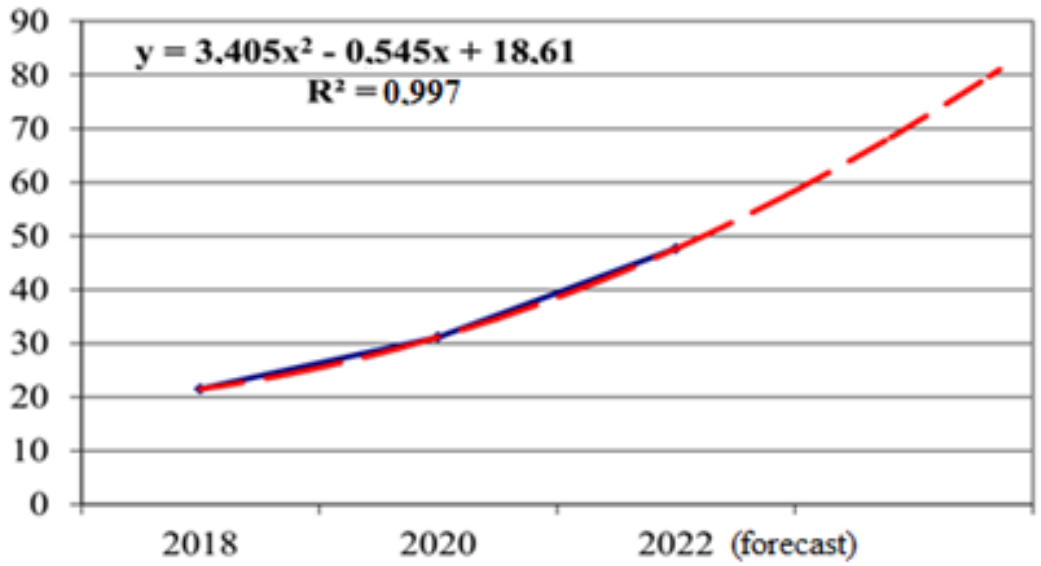

Figure 10. Integrated risk assessment of industrial enterprises of the "Valley of Mechanical Engineering" cluster. Developed by VertakovaYu.

In the course of the research, it was found that the future development of enterprises in the "Valley of Mechanical Engineering" cluster depends significantly on the prospects for the development of product markets. The processes occurring in the external environment generate a wide range of risks, in the structure of which it is advisable to consider such groups as cluster, state, global and natural risks. Based on the results of forecasting external risks, it was found that a group of state and global risks, in particular political, territorial and financial, are characterized by significant threats over the next 5 years.

\section{Conclusions}

We proposed and tested a methodology for a comprehensive assessment of the risks of cluster enterprises, based on a functional-target approach, according to which a cluster enterprise as a socio-economic system is considered as a set of three basic subsystems: management, production and financial and economic. On the basis of this approach, a balanced system of risk-oriented diagnostic indicators of the enterprise and its subsystems has been developed. It involves the study of the totality of providing and resulting indicators of the production, financial, economic and management subsystems and provides for a logical analysis of whether events can change the value of a particular indicator in such a way that it will lead to a deterioration in the corresponding resultant indicator.

On the basis of the proposed methodology, through an expert survey, an assessment of the risks of activities of enterprises in the "Valley of Mechanical Engineering" cluster was carried out, systematized by sources of origin and hierarchical levels. In the course of the study, a negative growth trend was revealed for most risks at all hierarchical levels (in the groups of internal, cluster, state and global risks).

Comprehensive diagnostics and risk assessment of cluster enterprises is a prerequisite for effective risk management. The proposed methodology was tested on the case of clusters of mechanical engineering enterprises, which are distinguished by a significant number of cooperation ties, meaning these clusters are complex. Applying the methodology to other types of clusters may require some refinement. This is the direction of further research. Directions for further research can also serve as: the development of automated tools for assessing and managing risks based on the proposed methodology; adapting it to risk management not at the level of enterprises and their associations but at the level of key business units. In addition, an interesting area of further research is the consideration of cross-border clusters, a feature of which is the different legal regulations of enterprises in the cluster that are located in different jurisdictions. 
Author Contributions: Conceptualization, Y.V.; methodology, Y.V. and I.I.; formal analysis, I.I. and E.L.; investigation, Y.V., I.I. and E.L.; resources, E.L.; writing-original draft preparation, Y.V., I.I. and E.L.; writing—review and editing, Y.V., I.I. and E.L.; visualization, E.L.; supervision, I.I.; project administration, Y.V. All authors have read and agreed to the published version of the manuscript.

Funding: This research received no external funding.

Informed Consent Statement: Not applicable.

Conflicts of Interest: The authors declare no conflict of interest.

\section{References}

Aven, Terje. 2016. Risk assessment and risk management: Review of recent advances on their foundation. European Journal of Operational Research 253: 1-13. [CrossRef]

Aven, Terje, and Thor Erik Nøkland. 2010. On the use of uncertainty importance measures in reliability and risk analysis. Reliability Engineering and System Safety 95: 127-33. [CrossRef]

Bell, Geoffrey. 2005. Clusters, networks, and firm innovativeness. Strategic Management Journal 26: 287-95. [CrossRef]

Cooke, Philip. 2001. Regional innovation systems, clusters, an the knowledge economy. Industrial and Corporate Change 10: $945-74$. [CrossRef]

Deif, Ahmed, and Ahmed Mohib. 2020. Temporary clusters: A new SME clustering management model. Journal of Modelling in Management 16: 486-505. [CrossRef]

Delgado, Mercedes, Michael Eugene Porter, and Scott Stern. 2014. Clusters, convergence, and economic performance. Research Policy 43: 1785-99. [CrossRef]

Feser, Edward. 1998. Old and New Theories of Industry Clusters. In Clusters and Regional Specialisation: On Geography, Technology and Networks. Norwich: Pion.

Folch-Calvo, Martin, Francisco Brocal-Fernández, Cristina González-Gaya, and Miguel Sebastián. 2020. Analysis and Characterization of Risk Methodologies Applied to Industrial Parks. Sustainability 12: 7294. [CrossRef]

Galtsova, Olga, Tetiana Pulina, and Oleh Holovko. 2020. The use of SWOT analysis methodology for complex evaluation of enterprises' cluster association development under globalization. Baltic Journal of Economic Studies 6: 163-70. [CrossRef]

Guzhin, Aleksandr Aleksandrovich, and Valentina Gennadievna Ezhkova. 2017. Risk management and risk management methods. Innovations and Investments 2: 185-89.

Havierniková, Katarína, and Jozef Klučk. 2019. The risks in the case of cluster cooperation and ways of their prevention: As seen by SMEs entrepreneurs. Ad Alta: Journal of Interdisciplinary Research 9: 114-19.

Havierniková, Katarina, and Marcel Kordoš. 2019. The SMEs' perception of financial risks in the context of cluster cooperation. Quantitative Finance and Economics 3: 586-607. [CrossRef]

Jankowiak, Anna. 2020. Differentiation of cluster policy instruments in individual phases of the cluster life cycle. Transformations in Business \& Economics 19: 414-28.

Keshk, Ahmed Mohamed, Ibrahim Maarouf, and Ysory Annany. 2018. Special studies in management of construction project risks, risk concept, plan building, risk quantitative and qualitative analysis, risk response strategies. Alexandria Engineering Journal 57: 3179-87. [CrossRef]

Martin, Ron, and Peter Sunley. 2003. Deconstructing clusters: Chaotic concept or policy panacea? Journal of Economic Geography 3: 5-35. [CrossRef]

Porter, Michael Eugene. 1998. Clusters and the new economics of competition. Harvard Business Review 76: 77-90.

Shidov, Andemirkan Hachimovich, Irina Yurievna Gedgafova, Bella Valerievna Kazieva, Svetlana Suadinovna Sizhazheva, and Zalina Khasanovna Shogentsukova. 2019. Improving the Methodology for Managing Innovation and Investment Processes of Cluster Entities. Journal of Organizational Behavior Research 4: 235-49.

Sun, Ruili, Tiefeng Ma, Shuangzhe Liu, and Milind Sathye. 2019. Improved Covariance Matrix Estimation for Portfolio Risk Measurement: A Review. Journal of Risk and Financial Management 12: 48. [CrossRef]

Tinyakova, Viktoriya, Natalia Morozova, Oksana Konovalova, Irina Proskurina, and Elena Falkovich. 2020. The cluster form of organization and the prospects for its application to provide the sustainable development of cooperative entrepreneurship. Revista Genero E Direito 9: 1092-103.

Turkina, Ekaterina, and Ari Van Assche. 2018. Global connectedness and local innovation in industrial clusters. Journal of International Business Studies 49: 706-28. [CrossRef]

Vertakova, Yulia, Irina Izmalkova, and Evgeniy Leontyev. 2019. Game theory for the formation of a cluster risk management strategy. E3S Web of Conferences 138: 02005. [CrossRef]

Vertakova, Yulia Vladimirovna, and Maria Gennadievna Klevtsova. 2016. Methodology for Cluster Identification in an Economic Territory. Economics and Management 12: 31-39.

Vertakova, Yulia, Yulia Polozhentseva, and Maxim Khlynin. 2014. Formation and development of industrial clusters. Technical and Technological Problems of Service 1: 92-99. 
Williams, Chester Arthur. 1989. Risk Management and Insurance, 6th ed. New York: McGraw-Hill.

Zaripov, Rushan Nazhipovich, and Ilnur Marsovich Murakaev. 2018. Features of constructing a system for identifying and assessing the risks of a high-tech corporation functioning using the example of the rocket and space industry. Economics and Entrepreneurship 11: 1155-59.

Zhang, Qingxia. 2017. A Study of Financial Acquisition Risk Identification and Prevention. Modern Economy 8: 475-83. [CrossRef] 